\title{
Justice and oral health - implications for reform: Part Two
}

SADJ May 2019, Vol. 74 No. 4 p208 - p211

PD Motloba1, NL Makwakwa², LM Machete ${ }^{3}$

\section{INTRODUCTION}

Part One of the series (April SADJ) provided a comprehensive overview of Justice. ${ }^{1}$ Part Two provides the application of these theories to oral health. In the first paper the evolution of Justice is traced back to Ancient Greece, through the testimony of Plato and Aristotle., ${ }^{2,3}$ Their view of Justice was influenced by the occurrences in the Republic. The interaction and interpretation of politics, law, God and Man in this society shaped the ancient notion of Justice.

These philosophers assert that a just society ought to "treat equals equally and unequals unequally". ${ }^{3,4}$ This is characterised by a lawful and fair state, with retributive (restorative) and distributive capacity. For Plato and Aristotle, Justice was necessary for a stable and thriving society. The Aristotelian egalitarian view of Justice was furthered by Christian medieval philosophers. Augustine and Aquinas held that God's law provided a blueprint for a just society. ${ }^{5-7}$ Hence their contention to treat all mankind equally is as intended by God.

Modern philosophers like Kant, Bentham and Mill represent a radical deviation from Christian and egalitarian

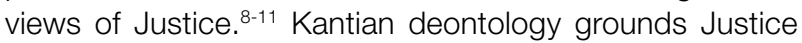
in the freedom or autonomy of moral agents, and the need to respect others to live their lives as they wish. Kant advocated for this moral imperative to be made universal law.

A diametrically contradictory view of Justice is proclaimed by Bentham and Hill. These consequentialists argue that an act is only Just when based on its utility or outcomes, hence their maxim 'greatest happiness for the greatest number'.

The contemporary interpretation of Justice to society and health is credited to Rawls and Daniels. According to

Author affiliations:

1. Pagollang D Motloba: BDS (Medunsa), MPH (Epidemiology) (Tulane), M Dent (Comm Dent) (Medunsa), MBL (Unisa), Chief Specialist, Head of Department Community Dentistry.* ORCID Number: 0000-0003-1379-7576

2. Nokukhanya L Makwakwa: $B D T, B D S$ (Medunsa) Postgraduate Dip in Clinical Dentistry (UWC), MPH (UL), Registrar, Community Dentistry.*

3. Motimedi L Machete: BDS (UL), MDS (SMU), Lecturer Community Dentistry.

*School of Oral Health Sciences - Sefako Makghatho Health Science University (SMU) Pretoria, South Africa.

Corresponding author: Pagollang D Motloba

HOD, Department of Community Dentistry, School of Oral Health Sciences-Sefako Makghatho Health Science University (SMU) Pretoria, South Africa.

Tel: +27 (0)12 5214848 Email: pagollang.motloba@smu.ac.za

\section{ACRONYMS \\ NHI: $\quad$ National Health Insurance \\ NOHD: National Oral Health Directorate \\ UHC: $\quad$ Universal Health Coverage}

Rawls, 8,12 a Just society which all would be part of is supported by the following Rawlsian fair principles:

(i) Equality of liberties, or freedom of choice, (ii) equality of opportunity, through the creation of a functional universal healthcare service and (iii) creation of a safety net, such as free health care services for the indigent. Daniels applied Rawls' aspiration of a just society to health, indicating the importance of it as a means to ensure equal and fair opportunities "...for all to realise their maximum species typical level of functioning".

The proverbial battleground of Justice represents a fierce contestation of moral viewpoints, without clear winners. Yet, winner(s) must emerge among the contenders to the applause of spectators. In case of oral health, this paper critiques the moral stance of the State, and the progress towards a just health service. Additionally, specific proposals are suggested on how to reform oral health in the country.

\section{State of Oral Health Services in South Africa}

Access to oral health services in South Africa is generally poor and inequitable. The two tier health care system is characterised by a costly and exclusive private sector, which offers limited choice to consumers and providers, with questionable oral health outcomes. The public sector remains under-resourced, overburdened and unable to meet the needs of South Africans. This dual funding of oral health reveals fundamental deficiencies and there are dire consequences of these two streams.

The private oral health service is experiencing a decline in insurance subscriptions, resulting in the reduction in the benefits packages of the patients. ${ }^{13}$ The limited private dental cover has caused patients to seek dental care in the public sector when the funds run out. This form of "patient dumping" is indicative of financial inequality and related health consequences. Until a uniform framework is developed oral health services will remain segregated.

Equally, the apportionment of public funding for oral health has dwindled over time. ${ }^{14}$ Additionally, misappropriation of oral health allocations is prevalent at all levels of public service delivery. Anecdotes reveal that oral health is comparatively least prioritised amongst other health services. As a consequence, the limited and or 
ring-fenced oral health resources are often redirected to "more deserving programs". Hence the failure (inability) of the oral health service to provide critical package of care to citizens.

At the organisational level, the National Oral Health Service is dysfunctional. Structurally, strategically and operationally, the office is obscure and inconsequential. The national coordinating office, viz. the National Oral Health Directorate (NOHD) has been repurposed and hollowed out and rendered obsolete.

Currently, the NOHD lacks the personnel and capacity to guide and lead a National Oral Health Service. By implication, this means that numerous national opportunities to reform and direct the national oral health agenda have been missed. Expectedly, the country lacks a coherent national oral health policy, strategy and structures to achieve the vision of "oral health for all". It is evident that national oral health structures operate asynchronously in the delivery of these critical oral health services. For instance, the Human Resources for Oral Health policy, ${ }^{15}$ and water fluoridation ${ }^{16}$ have not been implemented to date.

The National Oral Health Service is presently facing serious staffing challenges. The State has failed to enforce this critical human resources policy. Similarly, the universities have not transformed with regard to the training (production) of critical oral health personnel. Likewise, the services are unable to attract, deploy and retain the oral health professionals post-qualification or after community service. The unemployment rates are further compounded by high barriers which limit entry to private practice whilst the public sector is fully subscribed. These challenges have deepened the disproportional distribution of the oral health workforce away from the rural areas. The obvious consequences of these structural failures are poor service delivery and deterioration of the National Oral Health Service.

Meanwhile, the oral health disparities among South African are widening. These inequalities are fuelled by stark variations in socioeconomic resources, location, social position, discrimination and marginalisation. ${ }^{17-19}$

The oral health service is unable to respond to the definitional principle of access to care. These include acceptability, accessibility, adequate, appropriate and availability of services. South Africans are exposed to symptomatic and emergency dental care, mainly dental extractions.

Restorative and rehabilitatory services are infrequent, expensive or non-existent in most public facilities. The lack of these specialist services is indicative of the disparities by location, cost, and operation times. Health promotion and preventative services are in disarray and ineffective for impact. Overall, oral health services are beyond the reach of most South Africans.

This evidence points to an oral health system that is inaccessible, inequitable, discriminatory, unjust and unfair for the majority of South Africans. Hence a case for urgent reform of the oral health system.

\section{Towards Oral Health Reform in South Africa}

The following questions arise about the oral health service in South Africa:

1. What would be considered a just oral health system in South Africa? That is what stance or position or stature is held by the State, society and other role players about oral health. In other words how is the oral health service perceived, prioritised and compared with other health services.

2. What type and nature (structure and design) of oral health care system would be commensurate with a just service? A response to this question should provide information about the structural and strategic position of the sectors to deliver a just oral health service.

3. What existing or aspirational policies and principles would be supportive of a just oral health system?

4. What philosophy underpins the allocation of resources for oral health (equality, equity, need, liberty or free market)?

5. What operational and governance processes would ensure the delivery of a just health care system?

\section{Framework and Guidelines for a Just}

Oral Health System

The discussion of the framework and guidelines provides the perspective and outline for the critique of Oral Health Service. The argument is premised on the notion that a health system represents an interaction of interconnected building blocks to achieve a specific purpose, ${ }^{20,21}$ and that for a health system to functioning well, it will typically comprise the following structures:

1). Leadership and Governance, through which policy setting, regulation and oversight can be exercised over all other components.

2). Inputs factors including, financing, information systems, human resources, technologies and service delivery.

3). Outputs and outcomes such as access, health status and quality of life. ${ }^{22}$

These functions and attributes of a health system, its structures and operations should be aligned to ensure the delivery of the desired health service. Any failure in a single or several of these components would invariably render the delivery of health service unachievable.

However, these building blocks are necessary but not sufficient to deliver a just oral health system for all. As highlighted by Buchanan ${ }^{23}$ and Benatar in their seminal works, several key elements ought to be considered in developing a just health care system:

\section{Universal Health Coverage (UHC)}

This health system's objective is underpinned by a moral and legal obligation to ensure that all members of the community have universal access to a defined package of care. ${ }^{24}$

Implementing UHC is agreeable to several forms of Justice. For example, UHC appeals to equality be- 
cause at the very least all citizens have access to a minimum package of care. ${ }^{25}$ Similarly, this package satisfies the consequentialist doctrine of utility, by increasing access to the greatest number of patients. However, the limitation of the defined package is that it may not accommodate extraneous needs, and may limit freedom to choose.

Therefore, this proposal is contrary to the Kantian deontological view and the Libertarian assertion of free dom of choice. To mitigate this shortcoming, it has been suggested that this minimum package of care should be comprehensive and include promotive, preventive, curative, rehabilitative and palliative services.

Providing a comprehensive service builds some level of choice and alternative intervention, and in so doing the libertarian conception of Justice is satisfied, as well as an accommodation of varieties of needs.

This notion of decent (quality) minimum care implies that this level of care prescribed benefit is less than the best available, yet sufficiently acceptable to all. The health care services should be effective to ensure quality health outcomes. This will safeguard users from enduring additional burden, specifically financial liability.

\section{Capacities towards a just health care system}

It is evident that the chasm between the private and public health sectors represents a major threat to achieving equitable access to care. Hence the need for the State to deploy its resources to regulate and coordinate activities across these sectors.

Strategies like the National Health Insurance (NHI) could be used to purchase services from the private sectors, thereby increasing access. Change in the work ethic of public bureaucrat and public support for the project ought to be galvanised for a just health care system. Similarly, the professional altruism and duty should be stimulated in favour of common good.

Reforms towards a just health system will face huge impediments and resistance from professionals and business. A similar resolve and tenacity is necessary in oral health care system for the future generation. Operationally, the present delivery machinery should be re-engineered to incorporate efficiency and accountability.

Wastage should be minimised, while safe and effective quality care is provided as and when is necessary. Meaningful thrusts towards a just health system will not be achieved without deliberate investment in appropriate infrastructure; health information system; development, human resource and other building blocks. Entrenchment of culture of public service, accountability and productivity is equally essential.

\section{Continuity and coordination of services}

The oral health services should be organised in order to ensure uninterrupted continuity of care to patients. To achieve this objective, services should be coordinated based on the levels of care, across networks, according to types of care and providers, involving all related sectors and throughout life.

\section{Proposal for Oral Health Reforms in South Africa}

The following activities constitute an attempt to progressively reform the ailing oral health service in South Africa.

1. Reform in oral health requires a major paradigm shift, by the State and by all stakeholders. That is, the recognition that oral health is an essential contributor to overall health, and is therefore worthy of serious investment. A positive view on oral health will harness political and strategic alliances, galvanise the necessary resources and propel oral health to a visibly recognisable position.

2. Adoption of a singular and dominant funding structure for oral health, for example the $\mathrm{NHI}$.

3. Leadership and governance - creation of an integrated national, provincial and district oral health service.

4. The organisational structure for the delivery of oral health should be efficient and permit a development and seamless devolvement of national strategy to provinces, regions and local services.

5. Investment in infrastructure and technology in the Oral Sustainable and appropriate training and deployment of oral health professionals.

6. Gradual expansion of the existing public health services, until the whole population is covered.

7. Ensuring unrestricted access to a comprehensive list of emergency care by citizens.

8. Progressive introduction of restorative and rehabilitative services.

9. Strengthening of health promotion and preventive oral health services.

\section{CONCLUSION}

The path towards a transformed and just oral health service in South Africa is long and arduous. The journey is rewarding and necessary, but the means towards this objective are not guaranteed and require resolve and persistence.

\section{References}

1. Motloba P, Makwakwa N, Machete L. Overview of the moral theories of Justice: Part One. South African Dental Journal 2019; 74:150-2.

2. Allen RE. The Republic. Vol. 5. Yale University Press, 2006.

3. Young CM. Aristotle on Justice. The Southern Journal of Philosophy 1989;27 (Supplement):233-49.

4. Ross D, Ross WD, Brown L. The Nicomachean Ethics. Oxford University Press, 2009

5. Augustine S. The City of God. Hendrickson Publishers, 2008.

6. Lisska AJ. Aquinas's Theory of Natural Law: An Analytic Reconstrution. Oxford University Press, 1996.

7. O'Connor DJ. Aquinas and Natural Law. Macmillan International Higher Education, 1967.

8. Beauchamp TL, Childress JF. Principles of Biomedical Ethics. Oxford University Press, USA, 2001.

9. Mulgan T. Understanding Utilitarianism: Routledge; 2014.

10. O'Neill O. Kantian ethics. A companion to ethics 1993;29: 175-85.

11. Stratton-Lake P. Formulating categorical imperatives. KantStudien 1993; 84(3):317-40.

12. Rawls J. A Theory of Justice. Harvard University Press, 2009.

13. Erasmus D, Ranchod S, Abraham M, et al. Challenges and opportunities for health finance in South Africa: a supply and regulatory perspective. Johannesburg: FinMark Trust, 2016. 
14. White JG. Interacting forces influencing private dental practice in South Africa: implications for dental education. South African Dental Journal 2008; 63:80-5.

15. Padarath A, Ntuli A, Berthiaume L. Human resources. South African Health Review 2003; 299-318.

16. Chikte U. Promoting oral health in South Africa: public perceptions of water fluoridation. The Journal of the Dental Association of South Africa 1997; 52:665-71.

17. Ataguba JE, Akazili J, Mclntyre D. Socioeconomic-related health inequality in South Africa: evidence from General Household Surveys. International Journal for Equity in Health 2011; 10(1): 48.

18. Singh S. Dental caries rates in South Africa: implications for oral health planning. Southern African Journal of Epidemiology and Infection 2011; 26:259-61.

19. Abid A, Maatouk F, Berrezouga L, et al. Prevalence and severity of oral diseases in the Africa and Middle East Region. Advances in Dental Research. 2015; 27(1):10-7.

20. Bodenheimer T, Ghorob A, Willard-Grace R, Grumbach K. The 10 building blocks of high-performing primary care. The Annals of Family Medicine 2014; 12: 166-71.

21. Sachs JD. Achieving universal health coverage in low-income settings. The Lancet 2012; 380:944-7.

22. Mills A, Rasheed F, Tollman S. Strengthening Health Systems. Disease Control Priorities in Developing Countries 2006; 2 87-102.

23. Buchanan A. Privatization and just healthcare. Bioethics 1995; 9:220-39.

24. Campbell J, Buchan J, Cometto G, et al. Human resources for health and universal health coverage: fostering equity and effective coverage. Bulletin of the World Health Organization 2013; 91:853-63.

25. Gwatkin DR, Ergo A. Universal health coverage: friend or foe of health equity? The Lancet 2011; 377(9784):2160-1.

\section{Do the CPD questionnaire on page 212}

The Continuous Professional Development (CPD) section provides for twenty general questions and five ethics questions. The section provides members with a valuable source of CPD points whilst also achieving the objective of CPD, to assure continuing education. The importance of continuing professional development should not be underestimated, it is a career-long obligation for practicing professionals.

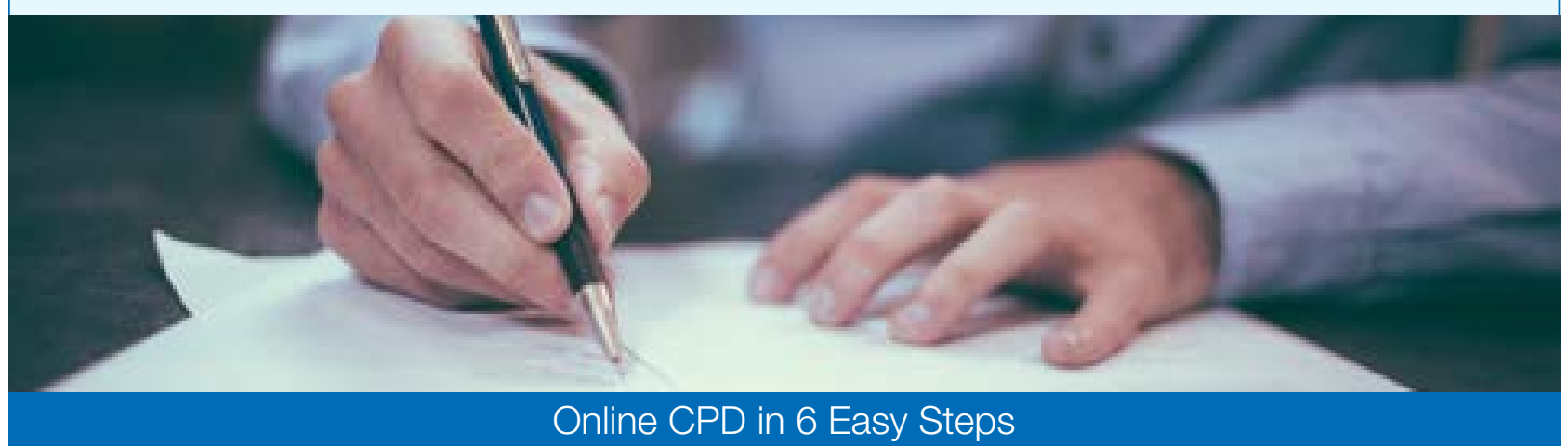

1 Go to the SADA website www.sada co za.

2 Log into the 'member only' section with your unique SADA username and password.

3 Select the CPD navigation tab.

4 Select the questionnaire that you wish to complete.

5 Enter your multiple choice answers. Please note that you have two attempts to obtain at least $70 \%$

6 View and print your CPD certificate. 